\title{
Boosting of photocatalytic hydrogen evolution via chlorine doping of polymeric carbon nitride
}

\author{
Malgorzata Aleksandrzak ${ }^{*}$, Michalina Kijaczko, Wojciech Kukulka, Daria Baranowska, \\ Martyna Baca, Beata Zielinska and Ewa Mijowska
}

\author{
Full Research Paper \\ Address: \\ Nanomaterials Physicochemistry Department, Faculty of Chemical \\ Technology and Engineering, West Pomeranian University of \\ Technology, Szczecin, Piastow Ave. 42, 71-065 Szczecin, Poland \\ Email: \\ Malgorzata Aleksandrzak* - mwojtoniszak@zut.edu.pl \\ * Corresponding author \\ § Tel: +48914496031 \\ Keywords: \\ chlorine; doping; hydrogen evolution reaction; photocatalysis; \\ polymeric carbon nitride
}

\author{
Beilstein J. Nanotechnol. 2021, 12, 473-484. \\ https://doi.org/10.3762/bjnano.12.38 \\ Received: 04 February 2021 \\ Accepted: 01 May 2021 \\ Published: 19 May 2021 \\ Associate Editor: W.-J. Ong \\ (C) 2021 Aleksandrzak et al.; licensee Beilstein-Institut. \\ License and terms: see end of document.
}

\begin{abstract}
Chlorine is found to be a suitable element for the modification of polymeric carbon nitride properties towards an efficient visiblelight photocatalytic activity. In this study, chlorine-doped polymeric carbon nitride (Cl-PCN) has been examined as a photocatalyst in the hydrogen evolution reaction. The following aspects were found to enhance the photocatalytic efficiency of Cl-PCN: (i) unique location of $\mathrm{Cl}$ atoms at the interlayers of PCN instead of on its $\pi$-conjugated planes, (ii) slight bandgap narrowing, (iii) lower recombination rate of the electron-hole pairs, (iv) improved photogenerated charge transport and separation, and (v) higher reducing ability of the photogenerated electrons. The above factors affected the 4.4-fold enhancement of the photocatalytic efficiency in hydrogen evolution in comparison to the pristine catalyst.
\end{abstract}

\section{Introduction}

Currently, the biggest problems of civilization seem to be the global energy crisis and environmental pollution. Both of these problems are directly related to each other. The pollution of our planet is mainly due to fossil fuels used in the energy industry, the combustion of which generates $\mathrm{CO}_{2}$ emissions.

The ideal solution of these problems appears to be the use of photocatalysis. The solar light, as a driving force, has been widely used in different fields, such as water in water-splitting to generate hydrogen [1-4], environmental remediation $[5,6]$, decomposition of organic pollutants [7], $\mathrm{CO}_{2}$ reduction into hydrocarbon fuels [8-10], disinfection [11,12], and selective organic transformations [13,14].

One of the most studied catalysts is polymeric carbon nitride $(\mathrm{PCN})$. This graphite-like semiconductor polymer, as a metal- 
free and visible-light-responsive photocatalyst, has attracted dramatically growing attention in the field of visible-light-induced hydrogen evolution reaction (HER). It is characterized by facile synthesis, easy functionalization, attractive electronic band structure, and photocatalytic activity [15-17]. Furthermore, it exhibits high thermal and chemical stability during photocatalytic reactions in the aqueous phase [18]. Unfortunately, its catalytic performance is mainly constrained by several typical challenges, which are the low density of reactive sites, nonresponse in the long-wavelength region, sluggish kinetics, and high recombination of photoexcited electron-hole pairs [19-21].

Tremendous efforts have been made in order to increase the photocatalytic activity of PCN materials by optimizing their nanostructure and improving their chemical surface texture. Three of the most popular modifications are: (i) coupling with other semiconductors [22,23], (ii) self-optimization of the crystal structure [24,25], and (iii) doping with heteroatoms $[26,27]$. Therefore, PCN is called the "holy grail" because it is believed that its modifications will result in obtaining a highly efficient HER under visible light conditions [28,29].

One of the most effective methods to modify the electronic structure and improve photocatalytic properties, among so many options, seems to be non-metallic doping [30-33]. For instance $\mathrm{Ma}$ et al. found that the doping of PCN with the $\mathrm{P}$ atom may promote the mobility of the charge carrier and facilitate the separation of the photogenerated electron-holes [34]. Another research group found that their prepared fluorinated carbon nitride has a photocatalytic activity 20.8 times higher than that of pristine PCN [30]. Wang et al. studied the photoactivity of $\mathrm{PCN}$ doped with $\mathrm{S}$ in the $\mathrm{CO}_{2}$ reduction reaction. The yield of $\mathrm{CH}_{3} \mathrm{OH}$ over the unit area of the photocatalyst was almost 2.5 times higher than of pristine PCN [35].

Recently, co-doping of $\mathrm{g}^{-} \mathrm{C}_{3} \mathrm{~N}_{4}$ with two non-metallic elements has been also studied. This strategy can enhance photocatalysis by imparting additional merits of each of the co-dopants of the photocatalyst. Polymeric carbon nitride has been co-doped with B/F [36], S/P [37], or C/P [38]. Yi et al. showed that PCN co-doped with $\mathrm{S}$ and $\mathrm{Cl}$ had better catalytic efficiency in the degradation of rhodamine B and 4-nitrophenol under visible light compared to catalysts doped with one heteroatom [39]. Other studies showed that S- and P-doped photocatalysts showed significantly increased photocatalytic activity in the degradation of methylene blue under visible light compared to bulk PCN. The improvement was attributed to lone-pair electron delocalization, efficient charge separation, favorable retention of the crystal structure, and light-harvesting extension [37].
Here, a new procedure of PCN doping with chlorine will be revealed. The photocatalytic activity of the prepared materials was investigated in a water-splitting reaction with hydrogen evolution under simulated solar light. A series of microscopic and spectroscopic techniques have been used to characterize the morphology, chemical structure, optical, photophysical, and electrical properties of the obtained carbon nitrides.

\section{Results and Discussion}

The detailed analysis of the morphology of the prepared materials, presented in Figure 1, was performed by transmission electron microscopy (TEM). The images of pristine PCN demonstrate the layered structure with a tendency to fold and aggregate. They also show several stacking layers, indicating the planar graphitic-like structure. After $\mathrm{Cl}$-doping, a relatively uniform-stacked petal-like nanosheet structure with small pores on the surface was formed (Figure 1). A higher magnification shows that in-plane mesopores of tens of nanometers are randomly distributed on the carbon nitride nanosheets (Figure 1d). The Cl-PCN porous structure allows for the catalyst to have a higher specific surface area and more active sites, which can simultaneously promote mass transfer and charge separation in nanodomains, thus optimizing the $\pi$-conjugated system for photochemical applications [40,41]. Furthermore, elemental mapping of nitrogen, carbon, oxygen, and chlorine in $\mathrm{Cl}-\mathrm{PCN}$ was performed and showed homogeneous distribution of all elements in the sample.

As analyzed via atomic force microscopy (AFM, Figure 2a and Figure $2 b$ ) the as-prepared PCN aggregated as large sheets with thickness ranging from 1 to $4 \mathrm{~nm}$ (corresponding to 3-11 atomic layers). In comparison, the Cl-doped PCN (Figure $2 \mathrm{c}$ and Figure $2 \mathrm{~d}$ ) revealed a thickness range from 0.5 to $5 \mathrm{~nm}$ (corresponding to 2-14 atomic layers) with the dominating fraction ranging from 2 to $4 \mathrm{~nm}$. The slight enlargement of the lattice parameters can be explained by the unique location of $\mathrm{Cl}$ atoms at the interlayers of PCN and not on its $\pi$-conjugated planes as it is in the case with other commonly used metal/nonmetal $(\mathrm{Cu}, \mathrm{Ni}, \mathrm{C}, \mathrm{N}$ or $\mathrm{O})$ modifications [42-46].

Fourier-transform infrared (FTIR) spectroscopy was used to obtain the molecular structure information of the carbon nitride materials. The FTIR absorption analysis was recorded in the spectral range of $600-3600 \mathrm{~cm}^{-1}$ to examine the surface of the prepared materials (Figure 3a). The FTIR spectra of both samples (before and after doping) reveal that the positions of the vibration peaks are nearly the same, indicating a similar molecular structure of the samples which is well maintained even after chemical doping of $\mathrm{Cl}$. The signal at $810 \mathrm{~cm}^{-1}$ represents the $s$-triazine ring models, which correspond to the condensed 

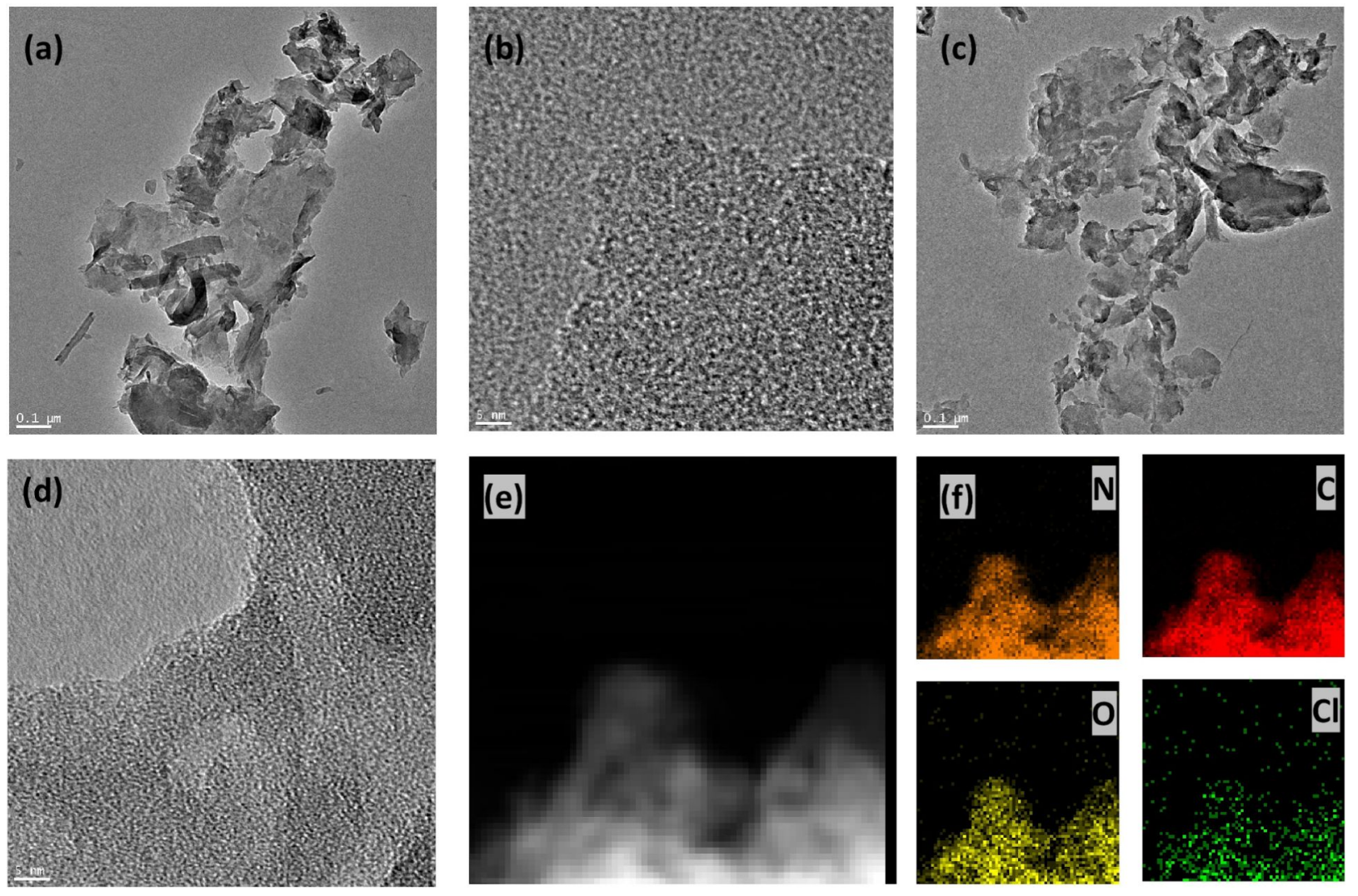

Figure 1: TEM images of PCN (a, b) and Cl-PCN (c, d). Scanning transmission electron microscopy image of $\mathrm{Cl}-\mathrm{PCN}(\mathrm{e})$ and energy-dispersive $\mathrm{X}$-ray spectroscopy (EDX) elemental mappings of $\mathrm{N}, \mathrm{C}, \mathrm{O}$, and $\mathrm{Cl}$ in $\mathrm{Cl}-\mathrm{PCN}$ (f).

$\mathrm{CN}$ heterocycles. The intense signal between 1200 and $1600 \mathrm{~cm}^{-1}$ is indicative of the characteristic stretching vibration of the $\mathrm{CN}$ heterocycles [47-49]. To be more specific, the peaks at 1241,1318 , and $1425 \mathrm{~cm}^{-1}$ are assigned to the aromatic $\mathrm{C}-\mathrm{N}$ stretching $[50,51]$ while the peaks at 1572 and $1637 \mathrm{~cm}^{-1}$ correspond to $\mathrm{C}=\mathrm{N}$ stretching [52]. The broad peaks in the range of $3000-3600 \mathrm{~cm}^{-1}$ correspond to uncondensed terminal amino groups $\left(-\mathrm{NH}_{2}\right.$ or $\left.=\mathrm{NH}\right)[53,54]$. The spectra do not show $\mathrm{Cl}$-containing functional groups, which can be attributed to their relatively low amount and the signal may be overlapped by the $\mathrm{CN}$ vibration.

The X-ray diffraction (XRD) patterns (Figure 3b) showed that both samples displayed a similar crystalline phase with two characteristic peaks at approx. $27.38^{\circ}$ and $13.28^{\circ}$, corresponding to (002) and (100) crystal planes for PCN, respectively. The (002) peak is associated with the typical interplanar stacking peak of conjugated aromatic structures, whereas the (100) peak is attributed to the in-plane packing motif of the tri-s-triazine units. The shift from $27.38^{\circ}$ to $27.30^{\circ}$ is caused by the increased internal distance of $\mathrm{PCN}$ by $\mathrm{Cl}$ doping, which is in good agreement with AFM data and suggests that $\mathrm{Cl}$ is located at the interlayers of carbon nitride. Moreover, the XRD and FTIR analyses confirmed that the $\mathrm{Cl}$ modification resulted in the maintenance of the chemical skeleton [43-47].

The chemical composition and relative atomic percentages of the obtained materials were analyzed by X-ray photoelectron spectroscopy (XPS). The XPS spectra revealed that the samples are composed of carbon, nitrogen, and oxygen. Additionally, the chlorine signal was detected in the doped sample. The atomic concentration of the elements was calculated assuming a homogeneous distribution in the analyzed surface layer and it is given in Table 1. The obtained results show that melamine polycondensation with 2-chloro-4,6-diamino-1,3,5-triazine (CDATA) increased the amount of carbon whereas it decreased the amount of nitrogen. Simultaneously, a slight increase in the atomic concentration of oxygen was observed. The XPS spectra revealed 0.18 atom \% of chlorine in Cl-PCN. The detailed analysis of the chemical components carbon and nitrogen was done by applying the peak-fitting procedure to the $\mathrm{N} 1 \mathrm{~s}$ and $\mathrm{C} 1 \mathrm{~s}$ spectra of the obtained samples and the results are shown in Figure 4 and in Table 2. The type of binding energy as well as the relative contribution of each component to the total area 
(a)

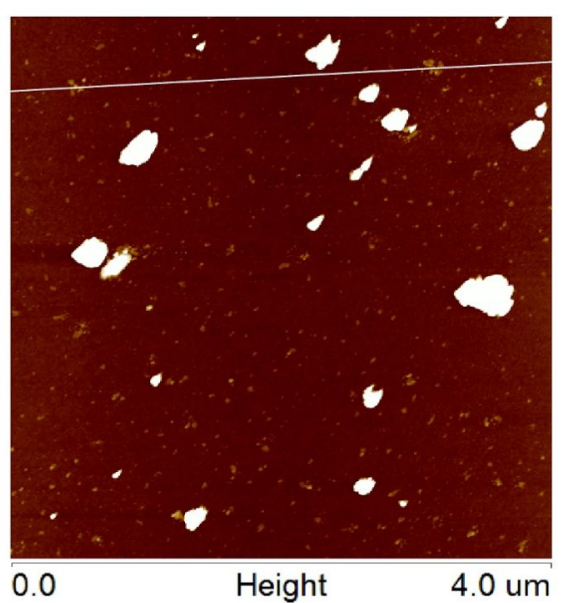

(c)

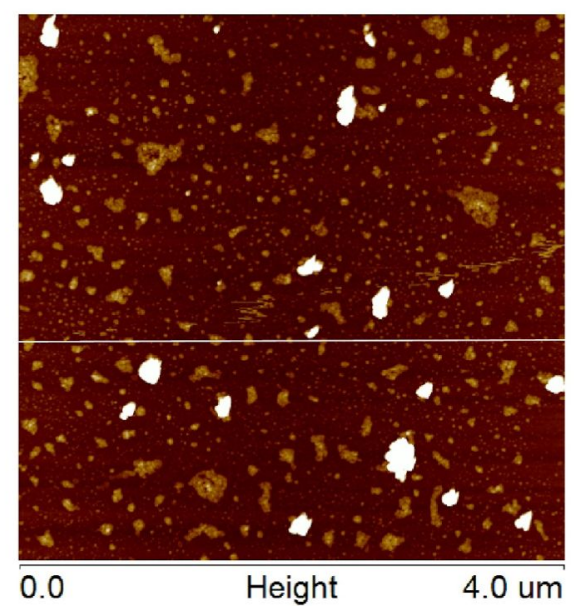

(b)

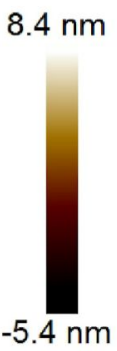

$10.6 \mathrm{~nm}$

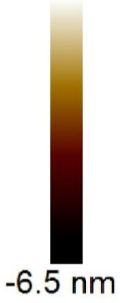

(d)

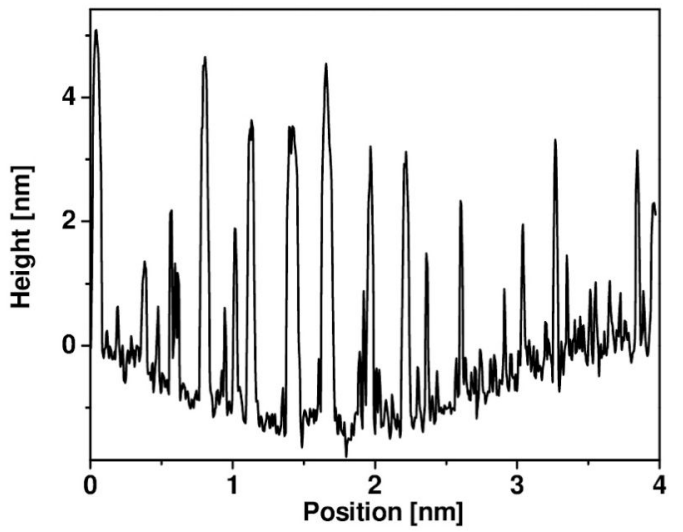

Figure 2: AFM images and height profile of $P C N(a, b)$ and $C I-P C N ~(c, d)$.

(a)

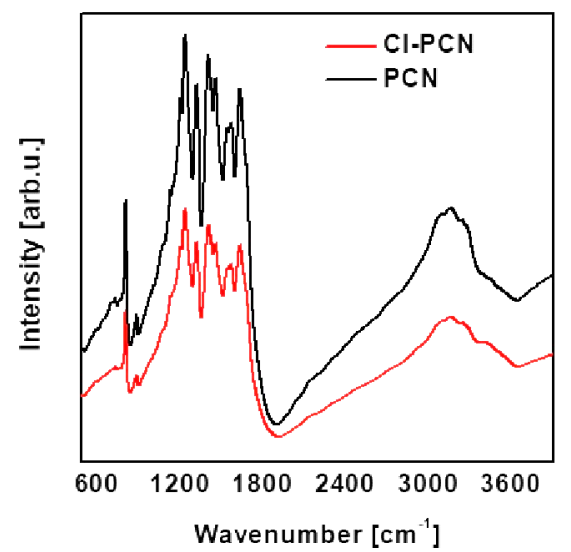

(b)

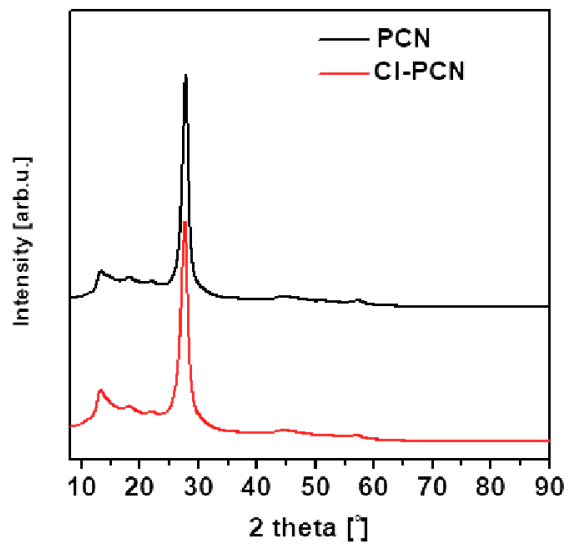

Figure 3: (a) FTIR spectra and (b) XRD patterns of PCN and CI-PCN. 
Table 1: $\mathrm{C}, \mathrm{N}, \mathrm{O}$, and $\mathrm{Cl}$ atomic concentration in $\mathrm{PCN}$ and $\mathrm{Cl}-\mathrm{PCN}$.

\begin{tabular}{lllll} 
Sample & $\mathrm{C}($ atom \%) & $\mathrm{N}($ atom \%) & $\mathrm{O}$ (atom \%) & $\mathrm{Cl}($ atom \%) \\
\hline PCN & 36 & 63.58 & 0.42 & - \\
Cl-PCN & 36.86 & 62.31 & 0.65 & 0.18
\end{tabular}

(a)

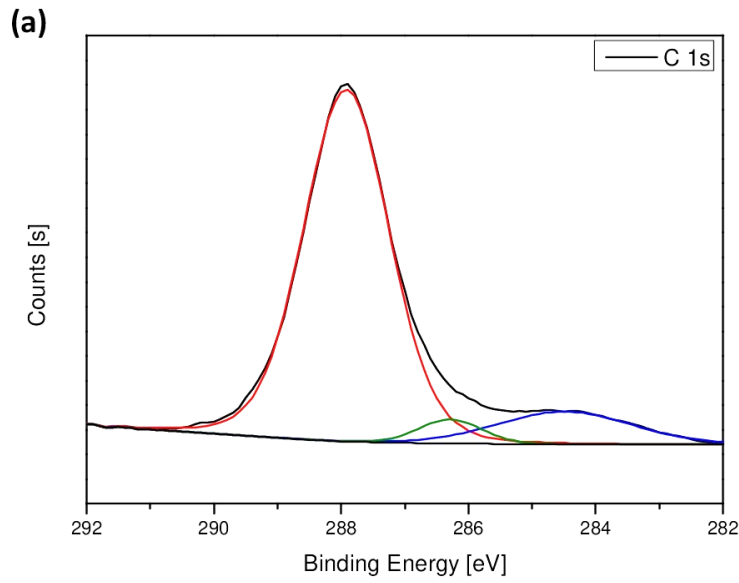

(c)

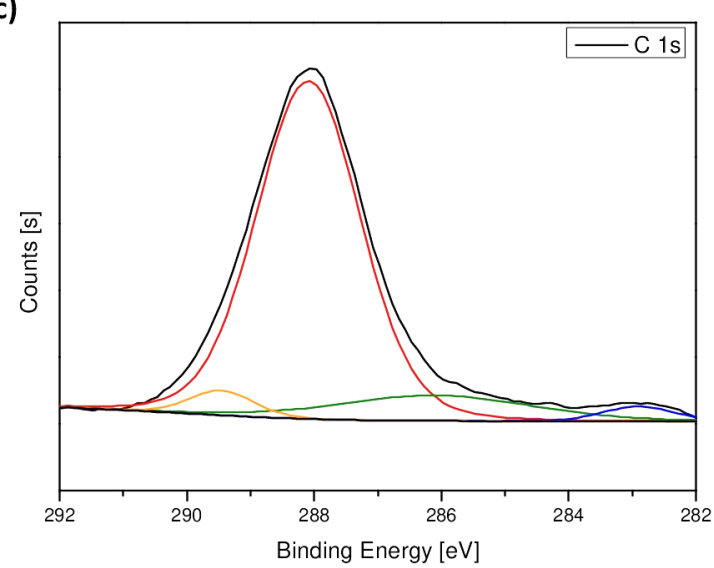

(b)

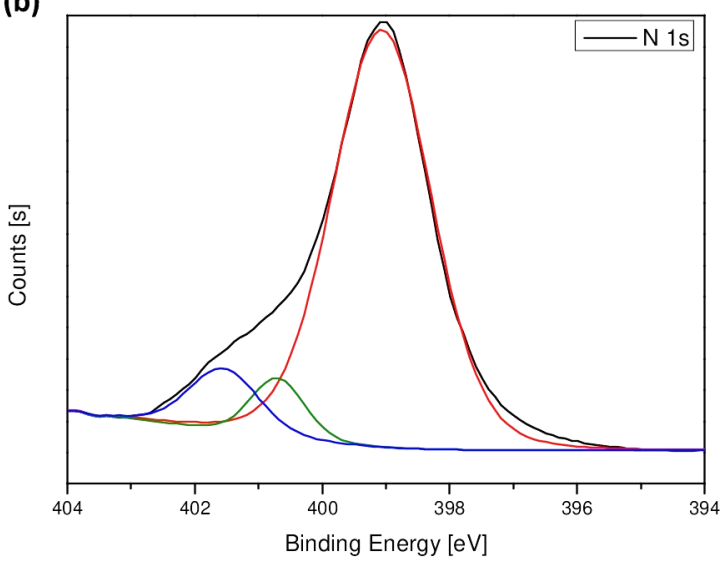

(d)

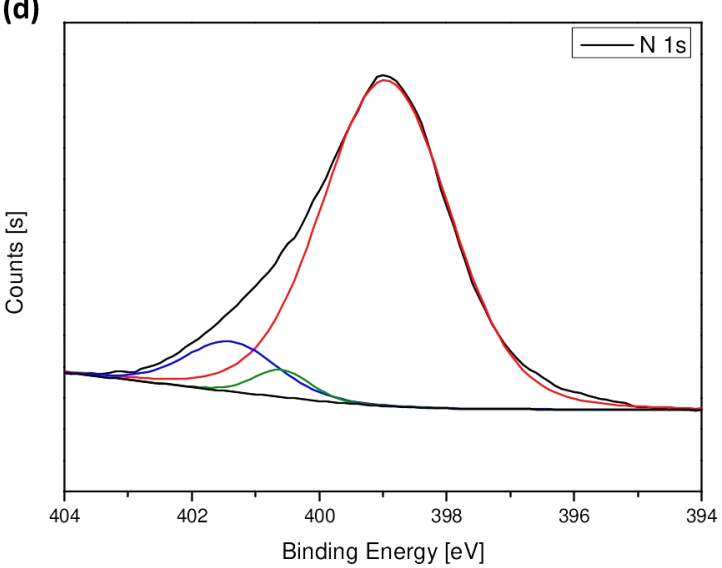

Figure 4: $\mathrm{C}$ 1s and $\mathrm{N}$ 1s XPS spectra of polymeric carbon nitride $(\mathrm{a}, \mathrm{b})$ and $\mathrm{Cl}-\mathrm{PCN}(\mathrm{c}, \mathrm{d})$.

Table 2: Chemical composition of $\mathrm{PCN}$ and $\mathrm{Cl}-\mathrm{PCN}$ calculated from the peak-fitting procedure applied to the $\mathrm{N} 1 \mathrm{~s}$ and $\mathrm{C} 1 \mathrm{~s}$ spectra of the samples.

\begin{tabular}{|c|c|c|c|c|c|c|c|}
\hline Sample & $\begin{array}{l}\mathrm{N}-\mathrm{C}=\mathrm{N} \\
\text { (atom \%) }\end{array}$ & $\begin{array}{l}\mathrm{C}-\mathrm{NH}_{x} \\
\text { (atom \%) }\end{array}$ & $\begin{array}{l}\mathrm{C}-\mathrm{C} / \mathrm{C}=\mathrm{C} \\
(\text { atom \%) }\end{array}$ & $\begin{array}{l}\mathrm{C}-\mathrm{Cl} \\
\text { (atom \%) }\end{array}$ & $\begin{array}{l}\mathrm{N}_{2} \mathrm{C} \\
\text { (atom \%) }\end{array}$ & $\begin{array}{l}\mathrm{N}-\mathrm{H}_{x} \\
\text { (atom \%) }\end{array}$ & $\begin{array}{l}\mathrm{N}_{3} \mathrm{C} \\
\text { (atom \%) }\end{array}$ \\
\hline PCN & 83.61 & 4.23 & 12.16 & - & 84.77 & 8.73 & 6.50 \\
\hline Cl-PCN & 82.13 & 2.49 & 11.67 & 3.71 & 87.23 & 9.54 & 3.23 \\
\hline
\end{tabular}

under the peak were calculated. Peaks located at approx. 399 and $288 \mathrm{eV}$ are assigned to signals from $\mathrm{N} 1 \mathrm{~s}$ and $\mathrm{C} 1 \mathrm{~s}$, respectively. The $\mathrm{C} 1 \mathrm{~s}$ region consists of three contributions which are associated to $\mathrm{C}-\mathrm{C}, \mathrm{N}-\mathrm{C}=\mathrm{N}$, and $\mathrm{C}-\mathrm{NH}_{x}$. The $\mathrm{N} 1 \mathrm{~s}$ region consists of three contributions which are associated to $\mathrm{C}-\mathrm{N}_{3}$ $\left(\mathrm{N}_{3} \mathrm{C}\right), \mathrm{N}-\mathrm{C}=\mathrm{N}\left(\mathrm{N}_{2} \mathrm{C}\right)$, and $\mathrm{N}-\mathrm{H}_{x}$. The sample $\mathrm{Cl}-\mathrm{PCN}$ presents an additional contribution at $289 \mathrm{eV}$, which is related to $\mathrm{C}-\mathrm{Cl}$. It can be observed that as a result of chlorine doping the content of $\mathrm{N}-\mathrm{H}_{x} / \mathrm{C}-\mathrm{NH}_{x}$ increases compared to the starting material. In the case of $\mathrm{Cl}-\mathrm{PCN}$, the content of $\mathrm{N}-\mathrm{C}=\mathrm{N} / \mathrm{N}_{2} \mathrm{C}$ bonds also increases. On the other hand, the amount of $\mathrm{C}-\mathrm{C} / \mathrm{C}=\mathrm{C} / \mathrm{N}_{3} \mathrm{C}$ significantly decreases. 
The XPS analysis indicates a successful incorporation of chlorine into the polymeric carbon nitride network. Without the doping agent melamine, thermal polycondensation leads to the formation of melon. We suppose that the presented synthesis procedure results in the substitution of the melamine molecule with 2-chloro-4,6-diamino-1,3,5-triazine to form Cl-doped melon, followed by further polycondensation leading to chlorine-doped polymeric carbon nitride. The substitution has an effect on the appearance of $\mathrm{C}-\mathrm{Cl}$ bonds in the PCN structure where chlorine atoms are located between the carbon nitride layers, as reported by other groups [39,55]. After doping with $\mathrm{Cl}$, the contribution of $\mathrm{C}-\mathrm{NH}_{x}$ bonds to the XPS signal decreased from $4.23 \%$ to $2.49 \%$ and that of $\mathrm{N}_{3}-\mathrm{C}$ bonds from $6.50 \%$ to $3.23 \%$, with a simultaneous increase of the $\mathrm{N}_{2}-\mathrm{C}$ contribution from $84.77 \%$ to $87.23 \%$. The schematic representation of the as-synthesized material structure is shown in Figure 5.

The porosity of polymeric carbon nitride and PCN doped with chlorine was tested by the $\mathrm{N}_{2}$ adsorption-desorption experiment. The typical IV isotherms with $\mathrm{H} 3$ hysteresis loops are observed in the samples, which is typical of mesoporous materials

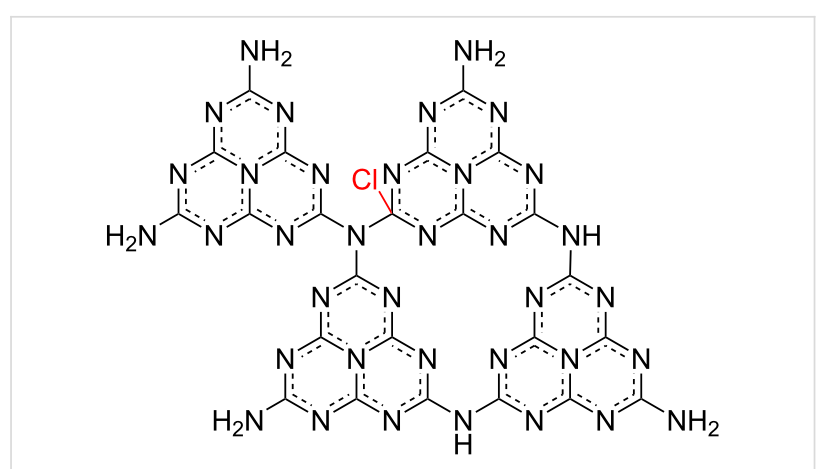

Figure 5: Structure of chlorine-doped polymeric carbon nitride.

(Figure 6). The hysteresis loops, pore-size distribution curves, and average pore diameter for both samples are similar. The proportion of micropores is small and the samples contain mainly mesopores. The sample modified by chlorine presents a slightly higher Brunauer-Emmet-Teller (BET) surface area, average pore diameter, and lower total pore volume. The details of the BET surface area, T-plot analysis results for micropore area, external surface area, total pore volume, and average pore diameter of PCN and Cl-PCN are presented in Table 3. (a)

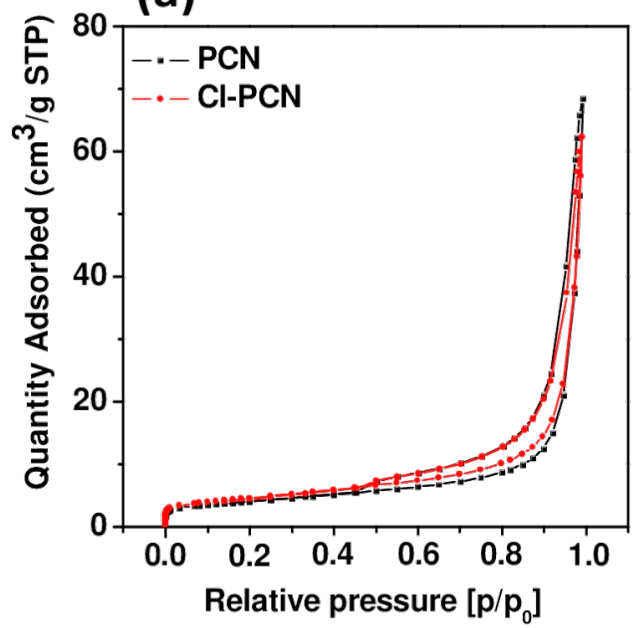

(b)

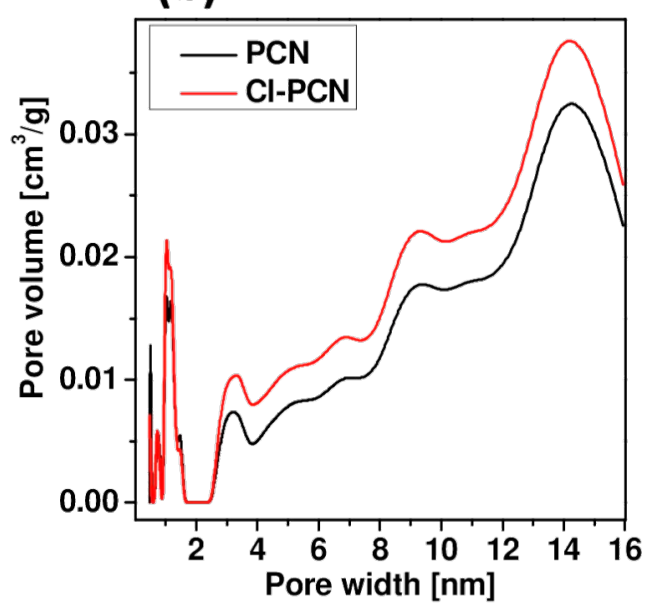

Figure 6: (a) Adsorption-desorption isotherms and (b) density functional theory (DFT) applied to the adsorption isotherms to obtain pore-size distributions of PCN and CI-PCN.

Table 3: BET surface area, T-plot analysis results for micropore area, external surface area, total pore volume, and average pore diameter of PCN and $\mathrm{Cl}-\mathrm{PCN}$.

\begin{tabular}{|c|c|c|}
\hline Sample & $\mathrm{PCN}$ & $\mathrm{Cl}-\mathrm{PCN}$ \\
\hline BET surface area $\left[\mathrm{m}^{2} / \mathrm{g}\right]$ & $14.43 \pm 0.02$ & $16.27 \pm 0.01$ \\
\hline T-plot micropore area $\left[\mathrm{m}^{2} / \mathrm{g}\right]$ & 2.06 & 1.94 \\
\hline T-plot external surface area $\left[\mathrm{m}^{2} / \mathrm{g}\right]$ & 12.37 & 14.32 \\
\hline total pore volume $\left[\mathrm{cm}^{3} / \mathrm{g}\right]$ & 0.106 & 0.096 \\
\hline average pore diameter [nm] & 5.65 & 5.76 \\
\hline
\end{tabular}


The results of the photocatalytic hydrogen generation process under simulated solar light irradiation is presented in Figure 7. It is clear that the designed modification of the samples strongly boosts the photocatalytic efficiency. The hydrogen evolution of $\mathrm{Cl}-\mathrm{PCN}$ was approx. 4.4 times higher after $3 \mathrm{~h}$ in relation to unmodified PCN. Therefore, chlorine doping is a reasonable strategy towards better photocatalytic hydrogen generation ability. To examine the stability of the photocatalytic activity of the Cl-doped carbon nitride, a recycle test has been performed. It revealed a decrease of approximately $2 \%$ in the $\mathrm{H}_{2}$ evolution rate after three cycles, indicating the stability of the catalyst.

Table 4 presents a comparative study of Cl-PCN with catalysts doped with $\mathrm{Cl}$ and other elements which have been reported in

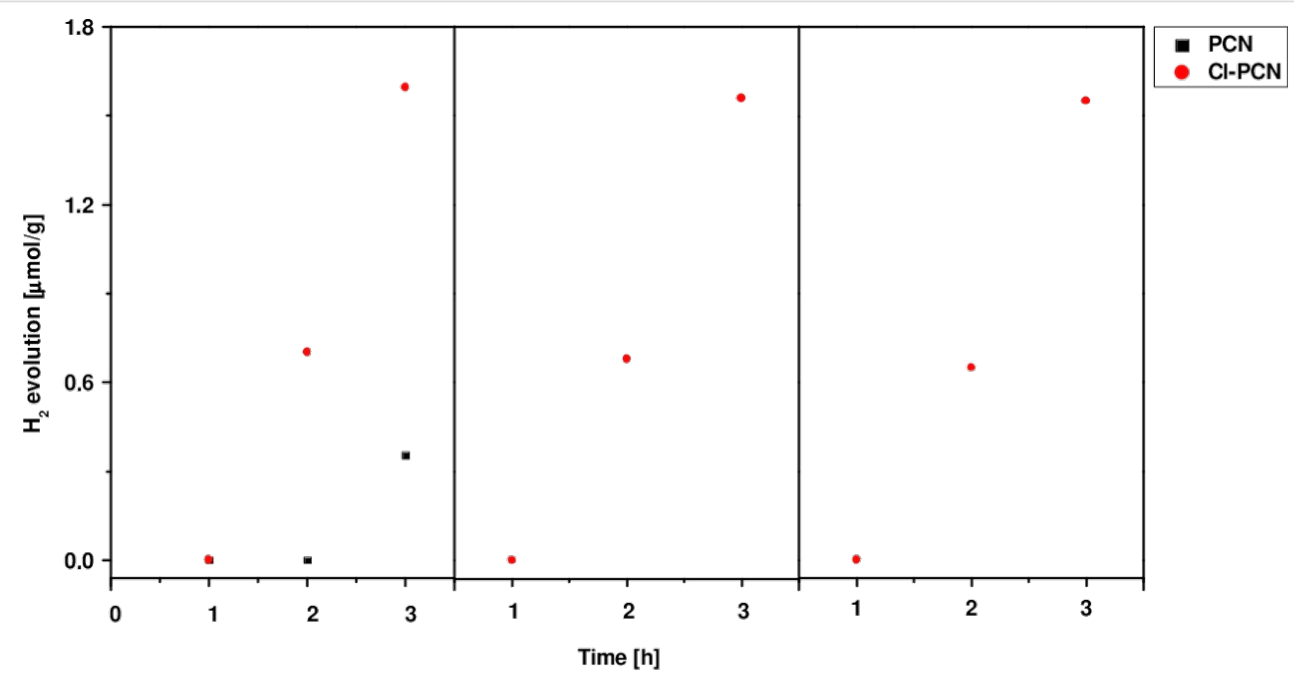

Figure 7: $\mathrm{H}_{2}$ evolution rate catalyzed by $\mathrm{PCN}$ and $\mathrm{CI}-\mathrm{PCN}$.

Table 4: Comparative study of the photocatalytic hydrogen evolution of $\mathrm{Cl}$ - PCN and other carbon nitride catalysts doped with other elements.

\begin{tabular}{|c|c|c|c|c|}
\hline Doping element & PCN precursor & Light & $\begin{array}{l}\text { Enhancement factor of HER over the } \\
\text { reference sample }\end{array}$ & Ref. \\
\hline $\mathrm{P}$ & melamine & $>420 \mathrm{~nm}$ & 4 & {$[57]$} \\
\hline$P$ & melamine & $>420 \mathrm{~nm}$ & 1.7 & [58] \\
\hline$P$ & melamine & $>420 \mathrm{~nm}$ & 9.5 & {$[59]$} \\
\hline $\mathrm{P}$ & melamine & $>420 \mathrm{~nm}$ & 8.6 & {$[60]$} \\
\hline S & melamine & $>420 \mathrm{~nm}$ & 1.9 & {$[58]$} \\
\hline $\mathrm{S}$ & dicyandiamide & $>420 \mathrm{~nm}$ & 8 & {$[61]$} \\
\hline S & urea & $>420 \mathrm{~nm}$ & 30 & {$[56]$} \\
\hline B & melamine & $>420$ nm & 2.7 & {$[58]$} \\
\hline$B$ & dicyandiamide & $>420 \mathrm{~nm}$ & 12 & {$[62]$} \\
\hline$B$ & melamine, urea & $>420 \mathrm{~nm}$ & 2.4 & [63] \\
\hline $\mathrm{O}$ & melamine & $>420 \mathrm{~nm}$ & 2 & [64] \\
\hline $\mathrm{F}$ & melamine & $>420 \mathrm{~nm}$ & 2.7 & [65] \\
\hline C & melamine & $>420 \mathrm{~nm}$ & 1.4 & {$[66]$} \\
\hline I & melamine & $>420 \mathrm{~nm}$ & 9 & {$[67]$} \\
\hline I & DCDA & $>420 \mathrm{~nm}$ & 2 & {$[68]$} \\
\hline I & DCDA & $>420 \mathrm{~nm}$ & 2 & [69] \\
\hline $\mathrm{Br}$ & urea & $>420 \mathrm{~nm}$ & 2 & [27] \\
\hline $\mathrm{Br}$ & urea & $>420 \mathrm{~nm}$ & 3.6 & {$[70]$} \\
\hline $\mathrm{Cl}$ & melamine & $>420 \mathrm{~nm}$ & 19.2 & {$[45]$} \\
\hline $\mathrm{Cl}$ & melamine & solar & 4.4 & this study \\
\hline $\mathrm{Mg} / \mathrm{Cl}$ & melamine & $>420 \mathrm{~nm}$ & 8.8 & [55] \\
\hline
\end{tabular}


the literature. The table presents a broad range of the enhancement factor of the hydrogen evolution rate after PCN doping. Among the presented doping procedures, S- and Cl-doping were found to enhance HER of PCN more significantly [45,56].

To explain the phenomenon of the enhanced photocatalytic $\mathrm{H}_{2}$ evolution after $\mathrm{Cl}$-doping more studies have been conducted. The optical properties of PCN and Cl-PCN were investigated via UV-vis diffuse reflectance spectroscopy (DRS) and photoluminescence (PL) emission spectroscopy. Figure 8a shows the Kubelka-Munk function curves of the fabricated materials. The bandgap is 2.78 and $2.77 \mathrm{eV}$ for PCN and Cl-PCN, respectively, indicating that the $\mathrm{Cl}$-doping had no significant effect on the bandgap shift. This might be attributed to the low content of chlorine atoms in the material.

The PL spectra of PCN and Cl-PCN are presented in Figure 8b. The emission peak of PCN is located at approx. $440 \mathrm{~nm}$, which is in accordance with the optical bandgap defined by the DRS measurement. Chlorine doping caused a slight redshift of the emission peak. Moreover, a reduction in the peak intensity was found, indicating a lower recombination rate of the electron-hole pairs, which is attractive in the photocatalytic process [44]. It shows that chlorine doping improves visible-light harvesting with PCN and promotes visible-light photocatalytic activity [55].

To estimate the valence band position of $\mathrm{PCN}$ and $\mathrm{Cl}-\mathrm{PCN}, \mathrm{VB}$ XPS spectra were measured and are presented in Figure 8c. Furthermore, the conduction band $(\mathrm{CB})$ position of the samples was calculated from the formula $E_{\mathrm{CB}}=E_{\mathrm{g}}-E_{\mathrm{VB}}$, and the band diagram is presented in Figure $8 \mathrm{~d}$. The VB and CB positions to the more positive potential after chlorine doping is shifted, indicating strengthened reducibility of electrons in $\mathrm{CB}$. This is one of the factors influencing the enhanced photocatalytic activity in the hydrogen evolution reaction. (a)

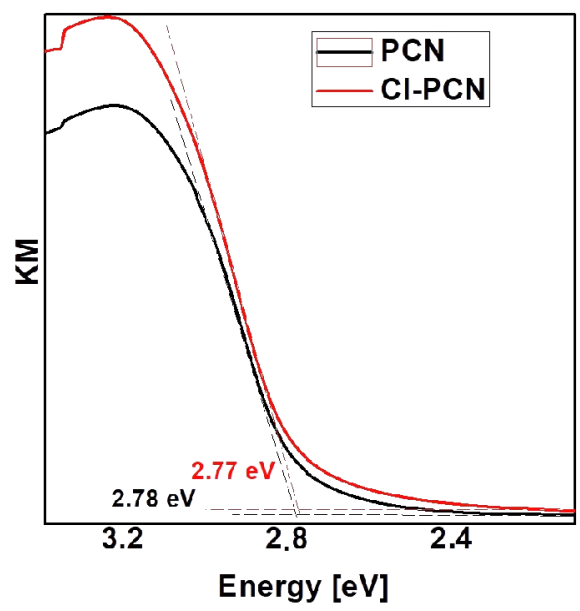

(c)

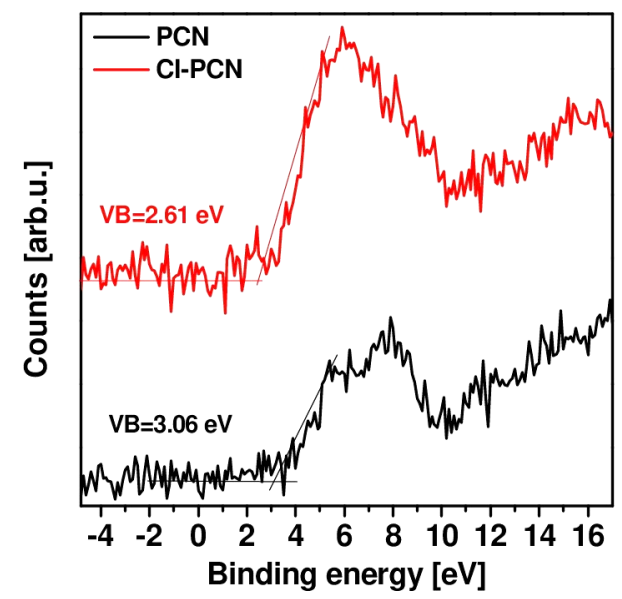

(b)

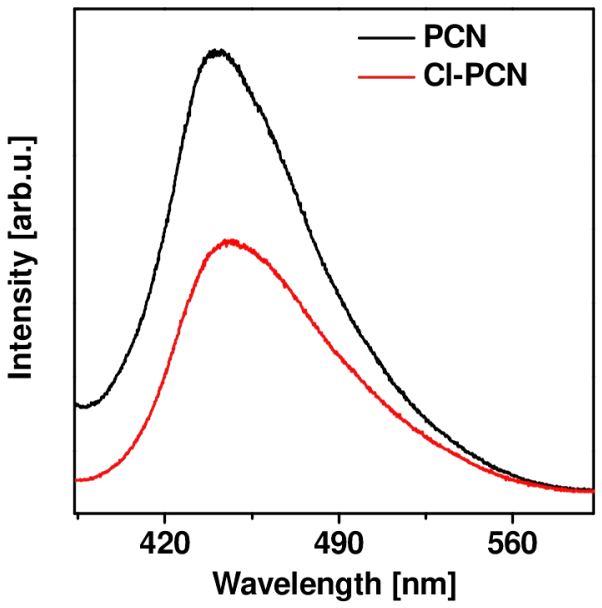

(d)

V vs. NHE

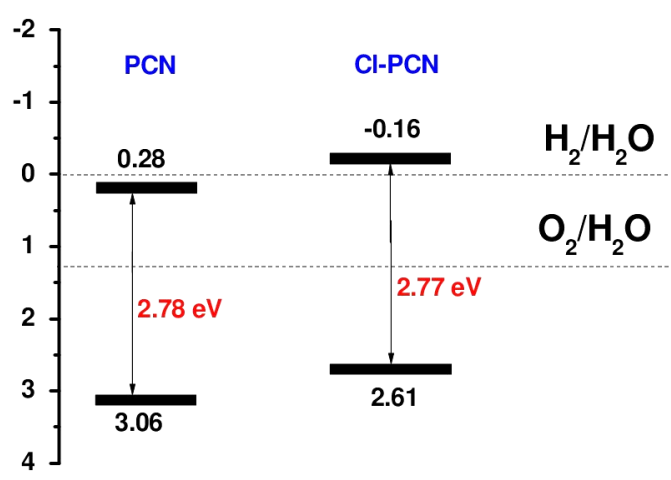

Figure 8: (a) DRS spectra, (b) PL emission spectra, (c) valence band (VB) XPS spectra, and (d) band diagram of PCN and CI-PCN. 
Figure 9a shows the transient photocurrent response of PCN and Cl-PCN. One can observe two-fold enhancement of the photocurrent response after chlorine doping of PCN. It demonstrates an improved generation of electron-hole pairs and better transportation of the charge carriers after modification. After three cycles of light on-off, the performance of both electrodes tends to stabilize, indicating that the photocatalysts are stable under visible-light irradiation [55].

The measurements obtained from electrochemical impedance spectroscopy (EIS) are shown in Figure 9b. It is known that the arc radius of the EIS spectrum is related to the charge-transfer resistance at the electrode-electrolyte interface [71]. The EIS arc radius of Cl-PCN is smaller than that of PCN. Its impedance is reduced compared to $\mathrm{PCN}$, indicating that $\mathrm{Cl}$ doping decreased the charge-transfer resistance of polymeric carbon nitride. It further indicates that $\mathrm{Cl}$ doping can promote transfer and separation of the photogenerated carriers [55], which agrees with the photoluminescence spectroscopy results and transient photocurrent response. The improved transport and separation can be affected by $\mathrm{Cl}$ atoms acting as a charge carrier transport bridge between the layers of carbon nitride [45,55].

The presented study revealed that the polycondensation of melamine with 2-chloro-4,6-diamino-1,3,5-triazine leads to formation of $\mathrm{Cl}$-doped polymeric carbon nitride. The presented material showed improved photocatalytic properties in the hydrogen evolution reaction from water compared to pristine PCN. The investigation showed that the enhanced photocatalytic activity was attributed to an improved photogenerated charge transport and separation. Here, chlorine atoms could act as a charge carrier transport bridge between the carbon nitride layers. Although $\mathrm{Cl}$ doping did not affect the reduction in the bandgap energy, the transient photocurrent response of Cl-PCN was enhanced compared to pristine PCN, indicating a better transport and separation of the photoinduced charges. It indicates that a higher amount of electrons can migrate to the surface reaction sites before recombination leading to hydrogen evolution. These results are consistent with PL spectroscopy and EIS results, revealing a better separation and charge transfer, respectively, after chlorine doping. Moreover, it was revealed that chlorine doping affected the $\mathrm{CB}$ shift to a more negative potential, resulting in photogenerated electrons with a higher reducing ability in the water splitting reaction and, consequently, with a higher efficiency in hydrogen evolution.

\section{Conclusion}

In summary, Cl-PCN nanosheets have been successfully synthesized via the polycondensation method. Fabricated 2D nanomaterials were used as photocatalysts for hydrogen evolution from water splitting. It was found that the $\mathrm{Cl}$-modification had an effect on the photocatalytic efficiency. Also, main aspects were revealed: (i) a unique location of $\mathrm{Cl}$ atoms at the interlayers of PCN and not on its $\pi$-conjugated planes, (ii) a non-reduction in the bandgap energy, (iii) a lower recombination rate of the electron-hole pairs, (iv) improved photogenerated charge transport and separation, and (v) an enhanced reducing ability of the photogenerated electrons. Therefore, it is believed that heteroatom doping of pristine PCN is a suitable strategy towards boosting photocatalytic hydrogen evolution.

\section{Experimental}

\section{Materials}

All purchased reagents employed for catalyst preparation were analytical grade and used without further purification.

\section{(a)}

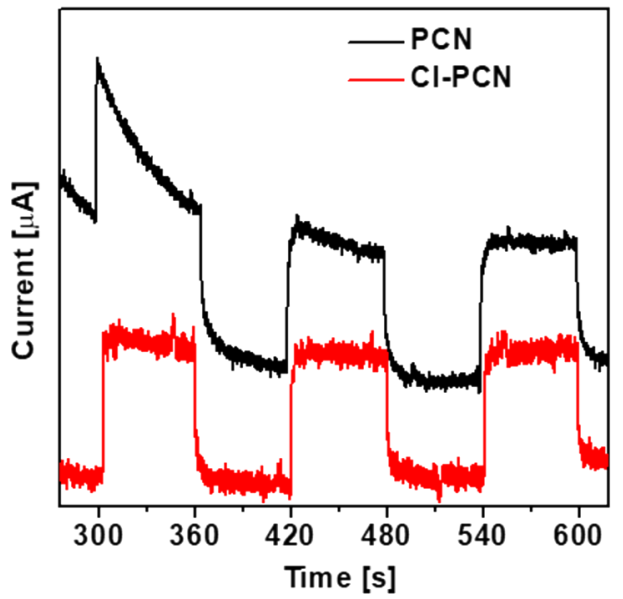

(b)

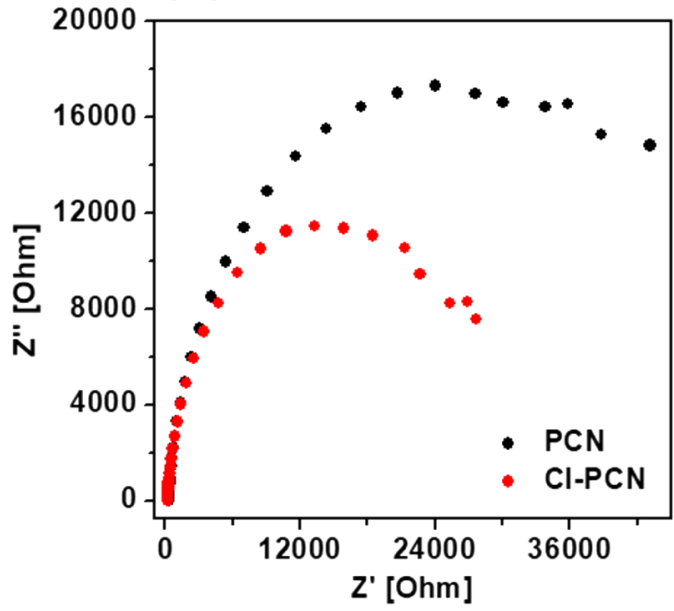

Figure 9: (a) Photocurrent response and (b) EIS spectra of PCN and CI-PCN. 


\section{Synthesis of polymeric carbon nitride}

Polymeric carbon nitride was synthesized by direct heating of melamine. A given amount of melamine was placed in a covered crucible in a muffle furnace and heated in static air to $550{ }^{\circ} \mathrm{C}$ with a ramping rate of $4{ }^{\circ} \mathrm{C} / \mathrm{min}$ and then was held at $550{ }^{\circ} \mathrm{C}$ for $4 \mathrm{~h}$. After the reaction, the furnace was cooled down to room temperature. The obtained PCN was collected and milled into powder in an agate mortar.

\section{Synthesis of Cl-doped polymeric carbon nitride}

As a precursor of chlorine, CDATA was used. Firstly, $4 \mathrm{~g}$ of melamine was mixed with $200 \mathrm{mg}$ of CDATA in $20 \mathrm{~mL}$ of deionized water, upon stirring, for $1 \mathrm{~h}$ at room temperature. The solutions were then dried at $80^{\circ} \mathrm{C}$ overnight. The obtained powders were ground in an agate mortar, placed into covered crucibles, and were submitted to thermal condensation under the same conditions as the PCN. The final products were milled in a mortar into a fine powder.

\section{Characterization}

The morphology of the samples was analyzed using TEM (Tecnai F30) with an accelerating voltage of $200 \mathrm{kV}$. The FTIR spectra were recorded on a Nicolet 6700 FT-IR spectrometer. The chemical composition and relative atomic percentages on the surface of the samples were studied by XPS. The measurements were conducted using $\mathrm{Mg} \mathrm{K} \alpha(h v=1253.6 \mathrm{eV})$ radiation in a Prevac (Poland) system equipped with a Scienta SES 2002 (Sweden) electron energy analyzer operating with a constant transmission energy $\left(E_{\mathrm{p}}=50 \mathrm{eV}\right)$. The analysis chamber was evacuated to a pressure below $5 \times 10^{-9}$ mbar. The PL spectra were measured using a fluorescence spectrophotometer (F7000, Hitachi) with an excitation wavelength of $280 \mathrm{~nm}$. The DRS was performed using a Jasco (Japan) spectrometer. The Kubelka-Munk function was used to calculate the bandgap energy. The photocurrent response and electrochemical impedance spectroscopy were measured using the Autolab PGSTAT302 N potentiostat in a three-electrode test cell with a platinum wire as the counter electrode and the saturated calomel electrode (SCE) as the reference. The working electrode was a fluorine-doped tin oxide (FTO) glass with the analyzed material drop-casted from a $0.2 \%$ ethanol/Nafion solution. A $0.5 \mathrm{M}$ sodium sulfate solution was used as the electrolyte. The photocurrent (chronoamperometry) test was measured at $0.5 \mathrm{~V}$ vs SCE and the EIS test was conducted at $0.15 \mathrm{~V}$ vs SCE.

\section{Photocatalytic test}

Prior to the photocatalytic test, each sample was prepared by dispersing $10 \mathrm{mg}$ of the photocatalyst in $20 \mathrm{~mL}$ of water and sonicating for $1 \mathrm{~h}$. The photocatalytic water splitting reaction was carried out in an outer irradiation-type reactor (Pyrex reac- tion vessel) connected to an argon source. After the reaction solution was placed in the reactor, $5 \mathrm{~mL}$ of lactic acid was poured into and purged with argon for air removal. Then, the reactor was irradiated with a Xe lamp $(150 \mathrm{~W})$ with an air mass filter (A.M. $1.5 \mathrm{G}$ ) to achieve a simulated solar light. The photocatalytic $\mathrm{H}_{2}$ evolution rate was analyzed by using a Young Lin 6500 gas chromatograph (GC, micro TCD detector, ValcoPLOT Molesieve $5 \AA$ fused-silica column, and Ar as a carrier). Each catalyst was tested for $3 \mathrm{~h}$. Every hour, $100 \mu \mathrm{L}$ of gas was withdrawn from the reactor and injected into the gas chromatograph to measure the amount of $\mathrm{H}_{2}$ evolved.

\section{Funding}

This work was financially supported by the National Science Center, Poland, under the SONATA program (no. 2015/19/D/ ST5/01920).

\section{ORCID ${ }^{\circledR}$ iDs}

Malgorzata Aleksandrzak - https://orcid.org/0000-0001-8654-3388 Wojciech Kukulka - https://orcid.org/0000-0003-2709-8741

Daria Baranowska - https://orcid.org/0000-0003-1969-8552

\section{Preprint}

A non-peer-reviewed version of this article has been previously published as a preprint: https://doi.org/10.3762/bxiv.2021.9.v1

\section{References}

1. Kudo, A.; Miseki, Y. Chem. Soc. Rev. 2009, 38, 253-278. doi:10.1039/b800489g

2. Hisatomi, T.; Domen, K. Nat. Catal. 2019, 2, 387-399. doi:10.1038/s41929-019-0242-6

3. Chen, X.; Shen, S.; Guo, L.; Mao, S. S. Chem. Rev. 2010, 110, 6503-6570. doi:10.1021/cr1001645

4. Maeda, K. ACS Catal. 2013, 3, 1486-1503. doi:10.1021/cs4002089

5. Zhang, H.; Chen, G.; Bahnemann, D. W. J. Mater. Chem. 2009, 19, 5089-5121. doi:10.1039/b821991e

6. Di Paola, A.; García-López, E.; Marcì, G.; Palmisano, L. J. Hazard. Mater. 2012, 211-212, 3-29. doi:10.1016/j.jhazmat.2011.11.050

7. Chatterjee, D.; Dasgupta, S. J. Photochem. Photobiol., C 2005, 6, 186-205. doi:10.1016/j.jphotochemrev.2005.09.001

8. Marszewski, M.; Cao, S.; Yu, J.; Jaroniec, M. Mater. Horiz. 2015, 2, 261-278. doi:10.1039/c4mh00176a

9. Yu, J.; Wang, K.; Xiao, W.; Chenga, B. Phys. Chem. Chem. Phys. 2014, 16, 11492-11501. doi:10.1039/c4cp00133h

10. Yu, S.; Jain, P. K. ACS Energy Lett. 2019, 4, 2295-2300. doi:10.1021/acsenergylett.9b01688

11. Malato, S.; Fernández-lbáñez, P.; Maldonado, M. I.; Blanco, J.; Gernjak, W. Catal. Today 2009, 147, 1-59. doi:10.1016/j.cattod.2009.06.018

12. Robertson, P. K. J.; Robertson, J. M. C.; Bahnemann, D. W. J. Hazard. Mater. 2012, 211-212, 161-171. doi:10.1016/j.jhazmat.2011.11.058

13. Shiraishi, Y.; Hirai, T. J. Photochem. Photobiol., C 2008, 9, 157-170. doi:10.1016/j.jphotochemrev.2008.05.001 
14. Lang, X.; Chen, X.; Zhao, J. Chem. Soc. Rev. 2014, 43, 473-486. doi:10.1039/c3cs60188a

15. Niu, P.; Zhang, L.; Liu, G.; Cheng, H.-M. Adv. Funct. Mater. 2012, 22 , 4763-4770. doi:10.1002/adfm.201200922

16. Zheng, Y.; Lin, L.; Wang, B.; Wang, X. Angew. Chem., Int. Ed. 2015, 54, 12868-12884. doi:10.1002/anie.201501788

17. Reddy, K. R.; Reddy, C. V.; Nadagouda, M. N.; Shetti, N. P.; Jaesool, S.; Aminabhavi, T. M. J. Environ. Manage. 2019, 238, 25-40. doi:10.1016/j.jenvman.2019.02.075

18. Ong, W.-J.; Tan, L.-L.; Ng, Y. H.; Yong, S.-T.; Chai, S.-P. Chem. Rev. 2016, 116, 7159-7329. doi:10.1021/acs.chemrev.6b00075

19. Zhang, J.; Sun, J.; Maeda, K.; Domen, K.; Liu, P.; Antonietti, M.; Fu, X.; Wang, X. Energy Environ. Sci. 2011, 4, 675-678. doi:10.1039/c0ee00418a

20. Tan, G.; She, L.; Liu, T.; Xu, C.; Ren, H.; Xia, A. Appl. Catal., B 2017, 207, 120-133. doi:10.1016/j.apcatb.2017.02.025

21. Wang, Y.; Wang, X.; Antonietti, M. Angew. Chem., Int. Ed. 2012, 51, 68-89. doi:10.1002/anie.201101182

22. Yu, W.; Xu, D.; Peng, T. J. Mater. Chem. A 2015, 3, 19936-19947. doi:10.1039/c5ta05503b

23. Zhou, S.; Liu, Y.; Li, J.; Wang, Y.; Jiang, G.; Zhao, Z.; Wang, D.; Duan, A.; Liu, J.; Wei, Y. Appl. Catal., B 2014, 158-159, 20-29. doi:10.1016/j.apcatb.2014.03.037

24. Wang, L.; Hong, Y.; Liu, E.; Wang, Z.; Chen, J.; Yang, S.; Wang, J.; Lin, X.; Shi, J. Int. J. Hydrogen Energy 2020, 45, 6425-6436. doi:10.1016/j.ijhydene.2019.12.168

25. Kang, Y.; Yang, Y.; Yin, L.-C.; Kang, X.; Liu, G.; Cheng, H.-M. Adv. Mater. (Weinheim, Ger.) 2015, 27, 4572-4577. doi:10.1002/adma.201501939

26. Yan, S. C.; Li, Z. S.; Zou, Z. G. Langmuir 2010, 26, 3894-3901. doi:10.1021/la904023

27. Lan, Z.-A.; Zhang, G.; Wang, X. Appl. Catal., B 2016, 192, 116-125. doi:10.1016/j.apcatb.2016.03.062

28. Liao, G.; Gong, Y.; Zhang, L.; Gao, H.; Yang, G.-J.; Fang, B. Energy Environ. Sci. 2019, 12, 2080-2147. doi:10.1039/c9ee00717b

29. Reddy, N. L.; Kumbhar, V. S.; Lee, K.; Shankar, M. V. Graphitic carbon nitride-based nanocomposite materials for photocatalytic hydrogen generation. In Nanostructured, Functional, and Flexible Materials for Energy Conversion and Storage Systems; Pandikumar, A.; Rameshkumar, P., Eds.; Elsevier: Amsterdam, Netherlands, 2020; pp 293-324. doi:10.1016/b978-0-12-819552-9.00009-9

30. Wang, Y.; Di, Y.; Antonietti, M.; Li, H.; Chen, X.; Wang, X. Chem. Mater. 2010, 22, 5119-5121. doi:10.1021/cm1019102

31. Hong, J.; Hwang, D. K.; Selvaraj, R.; Kim, Y. J. Ind. Eng. Chem. (Amsterdam, Neth.) 2019, 79, 473-481. doi:10.1016/j.jiec.2019.07.024

32. Jing, L.; Zhu, R.; Phillips, D. L.; Yu, J. C. Adv. Funct. Mater. 2017, 27, 1703484. doi:10.1002/adfm.201703484

33. Dang, X.; Yang, R.; Wang, Z.; Wu, S.; Zhao, H. J. Mater. Chem. A 2020, 8, 22720-22727. doi:10.1039/d0ta07794a

34. Ma, X.; Lv, Y.; Xu, J.; Liu, Y.; Zhang, R.; Zhu, Y. J. Phys. Chem. C 2012, 116, 23485-23493. doi:10.1021/jp308334x

35. Wang, K.; Li, Q.; Liu, B.; Cheng, B.; Ho, W.; Yu, J. Appl. Catal., B 2015 , 176-177, 44-52. doi:10.1016/j.apcatb.2015.03.045

36. Ding, K.; Wen, L.; Huang, M.; Zhang, Y.; Lu, Y.; Chen, Z. Phys. Chem. Chem. Phys. 2016, 18, 19217-19226. doi:10.1039/c6cp02169g

37. Hu, C.; Hung, W.-Z.; Wang, M.-S.; Lu, P.-J. Carbon 2018, 127, 374-383. doi:10.1016/j.carbon.2017.11.019
38. Wang, H.; Wang, B.; Bian, Y.; Dai, L. ACS Appl. Mater. Interfaces 2017, 9, 21730-21737. doi:10.1021/acsami.7b02445

39. Yi, F.; Gan, H.; Jin, H.; Zhao, W.; Zhang, K.; Jin, H.; Zhang, H.; Qian, Y.; Ma, J. Sep. Purif. Technol. 2020, 233, 115997. doi:10.1016/j.seppur.2019.115997

40. Liu, J.; Huang, J.; Zhou, H.; Antonietti, M. ACS Appl. Mater. Interfaces 2014, 6, 8434-8440. doi:10.1021/am501319v

41. Chen, S.; Duan, J.; Tang, Y.; Zhang Qiao, S. Chem. - Eur. J. 2013, 19, 7118-7124. doi:10.1002/chem.201300157

42. Zhao, D.; Chen, J.; Dong, C.-L.; Zhou, W.; Huang, Y.-C.; Mao, S. S.; Guo, L.; Shen, S. J. Catal. 2017, 352, 491-497. doi:10.1016/j.jcat.2017.06.020

43. Wang, N.; Fan, H.; Sun, J.; Han, Z.; Dong, J.; Ai, S. Carbon 2016, 109 , 141-148. doi:10.1016/j.carbon.2016.08.004

44. Han, E.-X.; Li, Y.-Y.; Wang, Q.-H.; Huang, W.-Q.; Luo, L.; Hu, W.; Huang, G.-F. J. Mater. Sci. Technol. 2019, 35, 2288-2296. doi:10.1016/j.jmst.2019.05.057

45. Liu, C.; Zhang, Y.; Dong, F.; Reshak, A. H.; Ye, L.; Pinna, N.; Zeng, C.; Zhang, T.; Huang, H. Appl. Catal., B 2017, 203, 465-474. doi:10.1016/j.apcatb.2016.10.002

46. Baca, M.; Rychtowski, P.; Wróbel, R.; Mijowska, E.; Kaleńczuk, R. J.; Zielińska, B. Sol. Energy 2020, 207, 528-538. doi:10.1016/j.solener.2020.07.006

47. Guo, F.; Shi, W.; Zhu, C.; Li, H.; Kang, Z. Appl. Catal., B 2018, 226, 412-420. doi:10.1016/j.apcatb.2017.12.064

48. Zheng, Y.; Liu, J.; Liang, J.; Jaroniec, M.; Qiao, S. Z. Energy Environ. Sci. 2012, 5, 6717-6731. doi:10.1039/c2ee03479d

49. Wang, X.; Blechert, S.; Antonietti, M. ACS Catal. 2012, 2, 1596-1606. doi:10.1021/cs300240x

50. Liu, J.; Liu, Y.; Liu, N.; Han, Y.; Zhang, X.; Huang, H.; Lifshitz, Y.; Lee, S.-T.; Zhong, J.; Kang, Z. Science 2015, 347, 970-974. doi:10.1126/science.aaa3145

51. Kuriki, R.; Sekizawa, K.; Ishitani, O.; Maeda, K. Angew. Chem., Int. Ed. 2015, 54, 2406-2409. doi:10.1002/anie.201411170

52. Wang, X.; Maeda, K.; Thomas, A.; Takanabe, K.; Xin, G.; Carlsson, J. M.; Domen, K.; Antonietti, M. Nat. Mater. 2009, 8, 76-80. doi:10.1038/nmat2317

53. Guo, F.; Shi, W.; Wang, H.; Huang, H.; Liu, Y.; Kang, Z. Inorg. Chem. Front. 2017, 4, 1714-1720. doi:10.1039/c7qi00402h

54. Su, F.; Mathew, S. C.; Möhlmann, L.; Antonietti, M.; Wang, X.; Blechert, S. Angew. Chem., Int. Ed. 2011, 50, 657-660. doi:10.1002/anie.201004365

55. Long, D.; Diao, W.; Rao, X.; Zhang, Y. ACS Appl. Energy Mater. 2020, 3, 9278-9284. doi:10.1021/acsaem.0c01619

56. Hong, J.; Xia, X.; Wang, Y.; Xu, R. J. Mater. Chem. 2012, 22, 15006-15012. doi:10.1039/c2jm32053c

57. Feng, J.; Zhang, D.; Zhou, H.; Pi, M.; Wang, X.; Chen, S. ACS Sustainable Chem. Eng. 2018, 6, 6342-6349. doi:10.1021/acssuschemeng.8b00140

58. Mishra, B. P.; Babu, P.; Parida, K. Mater. Today: Proc. 2021, 35 , 258-262. doi:10.1016/j.matpr.2020.05.567

59. Guo, S.; Tang, Y.; Xie, Y.; Tian, C.; Feng, Q.; Zhou, W.; Jiang, B. Appl. Catal., B 2017, 218, 664-671. doi:10.1016/j.apcatb.2017.07.022

60. Long, D.; Chen, W.; Zheng, S.; Rao, X.; Zhang, Y. Ind. Eng. Chem. Res. 2020, 59, 4549-4556. doi:10.1021/acs.iecr.9b06707

61. Liu, G.; Niu, P.; Sun, C.; Smith, S. C.; Chen, Z.; Lu, G. Q.; Cheng, H.-M. J. Am. Chem. Soc. 2010, 132, 11642-11648. doi:10.1021/ja103798k 
62. Thaweesak, S.; Wang, S.; Lyu, M.; Xiao, M.; Peerakiatkhajohn, P.; Wang, L. Dalton Trans. 2017, 46, 10714-10720. doi:10.1039/c7dt00933j

63. Chen, P.; Xing, P.; Chen, Z.; Lin, H.; He, Y. Int. J. Hydrogen Energy 2018, 43, 19984-19989. doi:10.1016/j.jjhydene.2018.09.078

64. Zeng, Y.; Liu, X.; Liu, C.; Wang, L.; Xia, Y.; Zhang, S.; Luo, S.; Pei, Y. Appl. Catal., B 2018, 224, 1-9. doi:10.1016/j.apcatb.2017.10.042

65. Zhu, B.; Zhang, J.; Jiang, C.; Cheng, B.; Yu, J. Appl. Catal., B 2017, 207, 27-34. doi:10.1016/j.apcatb.2017.02.020

66. Dong, G.; Zhao, K.; Zhang, L. Chem. Commun. 2012, 48, 6178-6180. doi:10.1039/c2cc32181e

67. Han, Q.; Hu, C.; Zhao, F.; Zhang, Z.; Chen, N.; Qu, L. J. Mater. Chem. A 2015, 3, 4612-4619. doi:10.1039/c4ta06093h

68. Zhang, G.; Zhang, M.; Ye, X.; Qiu, X.; Lin, S.; Wang, X. Adv. Mater. (Weinheim, Ger.) 2014, 26, 805-809. doi:10.1002/adma.201303611

69. Guo, Y.; Chen, T.; Liu, Q.; Zhang, Z.; Fang, X. J. Phys. Chem. C 2016, 120, 25328-25337. doi:10.1021/acs.jpcc.6b06921

70. Zhao, S.; Zhang, Y.; Wang, Y.; Zhou, Y.; Qiu, K.; Zhang, C.; Fang, J.; Sheng, X. J. Power Sources 2017, 370, 106-113. doi:10.1016/j.jpowsour.2017.10.023

71. Bu, Y.; Chen, Z.; Li, W. Appl. Catal., B 2014, 144, 622-630. doi:10.1016/j.apcatb.2013.07.066

\section{License and Terms}

This is an Open Access article under the terms of the Creative Commons Attribution License (https://creativecommons.org/licenses/by/4.0). Please note that the reuse, redistribution and reproduction in particular requires that the author(s) and source are credited and that individual graphics may be subject to special legal provisions.

The license is subject to the Beilstein Journal of Nanotechnology terms and conditions: (https://www.beilstein-journals.org/bjnano/terms)

The definitive version of this article is the electronic one which can be found at:

https://doi.org/10.3762/bjnano.12.38 